\title{
Rationalism and Naturalism: An interview with Dr. Edouard Machery
} Racionalismo y Naturalismo: Entrevista a Dr. Edouard Machery

\author{
RAFAEL FELIPE MIRANDA ROJAS ${ }^{\mathrm{a}}$ id
}

Dr. Edouard Machery: Distinguished Professor in the Department of History and Philosophy of Science at the University of Pittsburgh, the Director of the Center for Philosophy of Science at the University of Pittsburgh, a member of the Center for the Neural Basis of Cognition (University of Pittsburgh-Carnegie Mellon University), and an Adjunct Research Professor in the Institute for Social Research at the University of Michigan. His works focuses on the philosophical issues raised by psychology and cognitive neuroscience with a special interest in concepts, moral psychology, the relevance of evolutionary biology for understanding cognition, modularity, the nature, origins, and ethical significance of prejudiced cognition, the foundation of statistics, and the methods of psychology and cognitive neuroscience. He is also involved in the development of experimental philosophy, having published several noted articles in this field ${ }^{2}$.

\footnotetext{
${ }^{1}$ This interview was made thanks to the important support from CONICYT FONDECYT $N^{\circ}$ 11180422, and Post-doctoral scholarship BECAS CHILE N 74190016. I am very thankful to Dr. Edouard Machery for his kindness and intellectual honesty. Special thanks are due to Chanel Moffitt and her professional assistance.

${ }^{2}$ https://www.edouardmachery.com/

a Universidad Católica del Maule, Facultad de Ciencias Religiosas y Filosóficas, Talca, Chile. Doctor in Philosophy, e-mail: rafaelmirandarojas@gmail.com
} 
Rafael Miranda Rojas: First at all, please tell us where you grew up and how did you get involved on philosophical discussions. What was your first approach to philosophical questions? Was it in your childhood or when you were a teenager? What was the first book that you remember awakening your interest in philosophical questions? In a nutshell, please share with us your first experience with philosophy.

Great, as you know I'm French, born and raised in France. I did my undergraduate and graduate degree in France. So I lived with my family in the west part of France, in a small town, on the beach, it's an unremarkable town, except for its very beautiful beach. In France as you might know, we do have philosophy in the last year of high school. So we have one year of philosophy and philosophy is quite important for that year, it matters a bit, the grade you get in your philosophy exam is quite important. So I wanted to become a mathematician, before when I was in high school because I loved mathematics and I was pretty good at it, but when I discovered philosophy in my last year of high school it just changed everything, somehow I discovered a way of reasoning and being rigorous that was different, so it was just like math in that mathematics is very rigorous, you give agreements and proofs for theorems but in philosophy you give agreements too and you have to be rigorous. But it was a different form of rigor and I really fell in love with that, a way of being rigorous that goes beyond a mathematical proof and so I just decided to become a philosopher rather than become a mathematician and just after my first year of philosophy, and France in contrast to what's going on in the US, and I don't know exactly about your country, but in France you have to specialize in one domain, one area, when you go to university, so your first year of undergraduate, you go to university to become a philosopher, you do mostly philosophy, so you do that kind of thing, so I specialized in philosophy very early on. And the type of philosophy that I was doing was the type of philosophy that was dominant in France at the time, which was mostly history of philosophy, so that in high school, it was with a problem-centered type of philosophy, it was a lot of history of philosophy. We were reading about Descartes, on skepticism 
and views on skepticism, self-knowledge and views on self-knowledge, so there was a lot of history on philosophy, classic philosophers, Plato, Descartes, a lot of Kant, Kant is extremely important in French philosophical education, a bit of German idealism, a little bit of phenomenology but not very much, so really classic history of philosophy, pretty much no analytic philosophy, actually I didn't know what it was. A little bit of philosophy of science but not very much. So a very traditional way of doing philosophy and I was a teenager, so I was not a child, as a child I was more interested in math and literature, so really when I was 15, my last year of high school, 15-16 my last year, is when I discovered philosophy and there was no one book that I read, I read a lot of philosophy during that last year. But mostly classic philosophy. I read many of Plato's dialogs and I read Descartes' work (The Discourse of Method, also Meditation Metaphysics) I read a bit of Kant, as well as a bit of Nietzsche, and also read a bit of existentialist philosophy, also Sartre, a bit of Camus and Merleau-Ponty, so it was really quite a traditional French introduction to philosophy with knowing some of the great pieces from Plato to recent works. And I never came back once I put my finger into philosophy I never took it out; I've become a philosopher since then and never stopped doing philosophy. My love of philosophy has varied a little bit so I was very much in love with philosophy when I discovered it, very much in love in the first years, and that ties a little bit into to your second question.

\section{RMR: What do you remember of your first years in University, being an undergraduate student?}

Yes, I can tell you two things about that: the first one I was started to tell you, well let me give you a bit of background about how that works in France. So in France you have two parts of the system. After your high school you have an exam called the baccalauréat, which is the end of your high school education exam that you have to pass, if you pass it, it is not very difficult exam but you get a grade. If you pass it, you can go to university. And you can do one of two things, most people, pretty much everyone goes to university. Is pretty much free, everyone can go. A small proportion of people 
go to what is known as Lycée, it's higher school, to go there you have two years of training in Paris between high school, which is sort of a preparatory school. It is very competitive, it is very difficult, and that's where I went. So I went these two years between high school and École normale supérieure. I went. So I did those two years of training in Paris, and then I got accepted into it, that is where Sartre, Merleau-Ponty, Derrida got trained. Anyone in modern philosophy got trained there. So, I got trained there. So, my first two years, before going to the École normale supérieure, were preparatory time. It was extremely challenging, because it's an extremely competitive environment and people were out working 80 hours a week for two years. And you have to learn Latin, Greek, history of the world from 1848, philosophy, French literature, one foreign language. So you have to be trained on that and you will have an exam on all these disciplines, after your two years. To get into the École normale supérieure is extremely intense, to go there maybe two thousand/three thousand people apply and they get 50 or 60 people, it is a very competitive exam. So I did work a lot and I had outstanding teachers. Both in Philosophy, Greek, English, German, and History. So, it was a wonderful time of my life just because of the amount of things I was learning and the constant changes. And philosophy was part of that, the philosophy there was quite good, was quite problem-oriented, we were mostly learning how to write dissertations which is the French version of the essay in philosophy, a lot of history of philosophy as well; I was lucky I got into the École normale supérieure, which was a wonderful place. You are paid by the government, you become a civil servant. So, when I was 18 I was a civil servant, paid by the French government, to do my studies, and there is no exam, no requirements, you do whatever you want with your time, you get 4 years of salary in the middle of Paris. They trust you to make the best of that time, and that was really in some ways was a really interesting time, I did a lot things in history of art while I was there. So I got a degree in the history of art from the university. I did a bit of logic there and I got a degree in philosophy from the University of Paris La Sorbonne, so at the same time I was at the École normale supérieure which does not give a degree, but I was also at La Sorbonne at the same time that is where I got my degrees. So, I spent 4 years 
there and I did a lot of philosophy and history, so here again both at the Sorbonne and École normale supérieure the orientation was almost exclusively toward history of philosophy and a bit of phenomenology. So, I did quite a lot of history of philosophy and a bit of phenomenology. At the Sorbonne there was a lot of phenomenology going on. Very tough philosophy of science, no philosophy of cognitive science, no; so that was interesting, however it had a bad effect. I somehow got tired with philosophy. I felt it was not making very much progress, I thought we were doing too much history of philosophy and reading too much phenomenology which was very outdated. We spent very much rehashing Russell, Heidegger and Merleau-Ponty instead of working on philosophical questions. So I really got disappointed in philosophy. But I spent a year at that time in the US in Boston College, in Boston, and I was able to attend graduate seminars and other universities, MIT and Harvard, and I discovered analytic philosophy this way.

\section{RMR: In Boston?}

Yes, it was around 1997-1998. That's how I discovered a new type of philosophy and I fell in love with it. And also my love for philosophy, which had really been going down somehow got revived. When I came back I switched entirely the type of philosophy I was doing. I stopped doing history of philosophy and phenomenology and I moved entirely toward analytic philosophy, philosophy of science and philosophy of cognitive science. So a complete revolution during this year in the US. It was just before my graduate studies, so the timing was perfect. And with my undergraduate studies I was getting bored with philosophy; I discovered something new and got to get into it.

\section{RMR: So, then you decided to made a graduate career on philosophy of science?}

Well, my career was in philosophy of cognitive science, so my dissertation was on concepts and that came from two things. First when I came back from the US, I searched around to learn about cognitive science in Paris so I joined a few labs. I think 
that was at the time that I started to going to the Institut Jean-Nicod. I'm not exactly sure who told me to go to the Institut Jean-Nicod, that was also very important to my training because I met some of the people who exposed me to analytic philosophy, philosophy of cognitive science, philosophy of mind and philosophy of language (Joel Pust, inter alia). All the philosophers were at the time doing philosophy of language and philosophy of cognitive science, many of them were at Institut Jean-Nicod, and as a student I started to learn quite a lot. Also something that was very important in my training was meeting Philippe Schlenker ${ }^{3}$, he was a linguist and philosopher of language, at the time he was at USC and UCLA but he spent a year in Paris, and maybe that is why I got into Jean-Nicod. He taught me syntax and semantics and of course introduction to formal semantics. Then he had a graduate seminar where he was talking about his research paper. So at the time he was writing about monsters (type of monsters) across languages. So, I got really exposed to cutting-edge philosophy of language. So all that really reoriented entirely my trajectory and I worked on concepts because I got interested in Jerry Fodor, which I initiated when I was in the US at Boston college or when I got back, I don't exactly remember when I got into concepts. That's how I decided to specialize in philosophy of cognitive science. I started to learn quite a lot of psychology at the time.

\section{RMR: Then you decided to make a post graduate career: How did you take that decision, making a post graduate career, which factors influenced your decision?}

It's an interesting question because I've always known, since I was a boy, that I would become a professor. This has always been my goal, since I was 10 or 12, I knew I wanted to become a professor.

\footnotetext{
${ }^{3}$ See https://sites.google.com/site/philippeschlenkerhome/ 


\section{RMR: Why is that?}

I'm not totally sure. My family really valued intellectual work, so I was primed to value intellectual work.

\section{RMR: Were they teachers?}

No, my father was a physician. My mother worked a lot of jobs; she was a nurse for a while then a teacher; also, she was a psychoanalyst, so she got trained in psychoanalysis. So she did a lot of different works. My grandparents were high school teachers and my mother was a high school teacher as well. It's a little bit unclear why, I read this novel by Lodge, Changing Places, and I really loved it and I loved travelling, and the intellectual new you, I was really fascinated by Sartre and all the French intellectuals, all of which had connections to the academic world in one way or the other, so it really gave me a model. So when I was going to the École normale supérieure, this was the main road to become a professor in France and it still is, so it was very clear I was going to do a PhD in philosophy. So there wasn't a question about what I wanted, the question was would I be given the opportunity, and I got the fellowship, so I was able to do my $\mathrm{PhD}$ after the École normale supérieure.

\section{RMR: Did you know at that time what would be the topic of your research?}

After I came back it was pretty clear to me what I wanted, so I decided to work in the analytic tradition, and naturalist philosophy, and I was mostly interested in philosophy of cognitive science.

\section{RMR: How did you get to University of Pittsburgh?}

So when I was doing my PhD, I spent 2 years at Rutgers from 2001-2003, with some trips back to Europe. Working with Steve Stich, he was very important for my intellectual life, he became my mentor in every possible way. Then in 2003-2004, I needed an additional year, so I got a fellowship from the DAAD, which is a German foundation, to spend a year doing psychology, in Berlin, Germany. During this year of 
2003-2004, the academic year, my last year of my PhD, I applied to only one job, as there was a job of cognitive science at Pitt, so I applied to that one job and I got it. I only applied to one job because I had a few Post-docs lined up if I wanted. So I didn't have any pressure to get a job. I was very lucky, at the time, Pitt had a job and I had a good profile for it and they interviewed me, they liked me and they hired me. I mean I could not have done it without the support of many American philosophers and some European philosophers; Stich supported me and wrote for me. In Europe there were colleagues that also wrote for me. Weinberg and James Hampton from London also wrote for me, as I was their student. All these people I came to know throughout my studies, they were really important helping me get the job here at Pitt. It was the support of the people, famous philosophers, that really helped me get a job here. Luck matters, I mean I met Steve Stich by luck and he changed my life. Then I had a job offer at the right time, when I was finishing my $\mathrm{PhD}$ and I was a perfect fit for the job, so luck mattered too here. I don't want to say talent doesn't matter, just luck matters quite a bit, in having a successful career and having a successful life.

RMR: Please, tell us how do you understand the so-called experimental philosophy? Do you think that is a theory, a cluster of theories, a movement, a specific methodology applied to philosophical problems? What is the link, if there is any (from your point of view), between Experimental Philosophy and Philosophy of Science?

XPhi philosophy is many things and it can be viewed as many things. So the way I like to think about it is to have a very broad conception of experimental philosophy. For me experimental philosophy is just the use of experimental and every more broadly empirical methods to study questions that are of relevance to philosophy; it is very broad. I do things that often in philosophy involve empirical claims. In fact, I think that the most interesting philosophy involves empirical claims, and philosophy that does not involve empirical claims tends to be boring. So I think the most interesting philosophy is connected to claims about the actual world. To the extent that philosophical 
argument can argue through empirical claims, we need to find out the truth of these empirical claims. Sometimes scientists have done the work for us, sometimes they haven't, and sometimes we can make interesting empirical contributions — in addition to learning about things that are relevant for philosophy. So, in my view experimental philosophy is really very broad, it is just taking very seriously the empirical commitment of philosophical thinking. Being an experimental philosopher is just really trying to take into account everything, both the philosophical argument and also some of the empirical steps in argumentation, and to do the empirical work when no one else is doing it. And not beg the question, don't make up the facts. That's really the broad conception. There's a narrower conception that just focuses on thought experiments and philosophy, that's a narrower conception, concerning how you would like people to answer such experiments in philosophy. I think it is too narrow of a conception for this type of philosophy. In that sense, for me experimental philosophy is really a continuation of naturalism in philosophy, it is a broad conception of experimental philosophy is one piece with a naturalistic attitude in philosophy.

Now you asked me what is the relationship of Experimental Philosophy and philosophy of science, it's a bit complicated and at the beginning, one might have thought philosophy of science would be very friendly to experimental philosophy, because many of them are naturalists too. But in fact the relationship has not been easy. I think many philosophers of science have no patience or sympathy for experimental philosophy, mostly because they view experimental philosophy through a narrow lens; they view it as just a study of judgments about thought experiments and they think it is irrelevant for what they do. They do not care about thought experiments, they don't care about what the folk say; they only care about scientific theories and that kind of questions.

I don't think philosophy of science has been very supporting to experimental philosophy since its beginning. They haven't been hostile but they haven't been very friendly either. There's a way to apply experimental philosophy through philosophy of science and I have been arguing that we should be doing that occasionally. I wrote a 
chapter on this sort of philosophy of science. I think that there are various questions in philosophy of science that call for empirical methods, so this is a broadening of the kind of tools philosophers of science can be using to answer the questions they are interested in, exactly the same way that experimental philosophers are using. So my view is that experimental philosophy is not a theory, it is not a cluster of theories, it is really the idea that we should broaden the kind of tools we have because some of the questions call for other forms of tools, as the one we've been training to use.

RMR: In some papers and books you express a skepticism concerning the goals and methods of the so-called armchair philosophy? Do you see armchair philosophy as philosophy without evidence? Is there any way in which armchair philosophy could make some contribution to experimental philosophy, or is it definitively flawed?

I'm not up on armchair philosophy, unless you mean armchair philosophy as thinking or theorizing from the armchair. I have no objection against theorizing. I think any activity of science or philosophy does involve thinking through things and thinking about problems and solutions. And all of that is done from the armchair. So, here is nothing wrong in the sense of being in an armchair and theorizing. What is wrong is two things: On the one hand, making up facts. So when some arguments, some questions or some debates rely on matters of facts, making up the matters of facts is wrong. I think some traditions within traditional philosophy have this tendency to just make up facts. What is wrong too is to ignore empirical findings that have methodological consequences for what one does. Let me just explain a little bit of what I mean about that. I had been arguing in many places and in my book Philosophy Within Its Proper Bounds, that thought experiments are an unreliable judgement and we'll talk a little about that soon, and my arguments are based on empirical findings, so I think what is wrong here is to "keep doing" - when philosophers keep doing what they are doing, using the same sort of experiments, ignoring a range of empirical findings that at the very least, maybe it's not this easy, but at the very least ask questions about what it 
is they're doing. So it is not that armchair philosophy is wrong, in fact armchair philosophy is perfectly fine as a component of philosophy, what is wrong is to reduce philosophy to armchair philosophy, to a thing that does nothing more than theorizing the things of the world. That is what I think is really wrong. That's what I've been very critical of for pretty much two decades.

RMR: So is there a way in which armchair philosophy could accomplish some of the targets of experimental philosophy from theorizing?

Absolutely, I have no objection to theorizing, so for example when we experimental philosophers do an experiment, we collect data, people from the armchair have been very useful in criticizing these experiments. They may say "Look, here's a possible interpretation of your findings", and I think, you know, some of the armchair

philosophy can be actually useful in some respects or others. There is nothing wrong with the armchair. Look, any science has an armchair component, armchair physics is not useless, armchair physics is theoretical physics, and there's nothing wrong with theoretical physics, armchair biology is theoretical biology, to theorize and develop models about the assumptions of the forces that play in nature, and models of the evolution of population given such assumptions. There's nothing wrong with that. I think the same is true for traditional philosophy, there's nothing wrong with traditional philosophy providing it is sufficiently responsive to empirical findings. What I really get upset, what I really dislike about it is when philosophers are not responsive to empirical findings. I think that it is easy, when you are a traditional philosopher or an armchair philosopher, to just ignore these empirical findings.

\section{RMR: Is there a kind of epistemic responsibility from armchair philosophy to not put the things onto empirical data?}

Yes, I think it is an epistemic duty to pay attention to empirical data. I think there is a lack of intellectual honesty in philosophers who just ignore that or philosophers who dismissed it or philosophers that mischaracterize the empirical 
results in order to keep doing whatever it was they were doing. So I just think there is a thing as intellectual honesty and it is an important virtue for me. And being open to empirical results is a component of that.

RMR: In your last book, Philosophy Within Its Proper Bounds, you talk about proper bounds on philosophy: How do you understand these bounds? These bounds could be, eventually, expanded? If so, how? If not, why?

The question here is, the question of the book is about the knowledge of metaphysical necessity and the bound is about how many metaphysical necessities that are relevant for philosophical theorizing can be known, and the plan is that the answer is very little. So, many of the metaphysical necessities that philosophers hope to know how to solve or resolve, many philosophical issues such as physicalism and dualism to assess reduction, many of them plan to assess metaphysical necessary principles. All these metaphysical necessities I argue are beyond our academic reach and I'm fairly skeptical that it can be expanded. I mean, here, my question would always be how would we know then, what are the methods to know about metaphysical necessities. In the book I look at a few possible answers to that question and I found that there is no good method to know about these metaphysical necessities. So we should come to view, to know, and to conclude that there are questions that we can't answer. That we'll never be able to find out whether physicalism or dualism is true, and so on and so forth.

\section{RMR: Concerning metaphysical necessity: How do you see the laws of nature for example, do you think they are metaphysically necessary?}

That's a metaphysical plan, so it is close. I do believe that they are metaphysical and necessary, that there could not be a possible world where the laws of nature held. It's hard for me to imagine how we would establish that claim. Just again it's beyond the bound of what we can know. In the book, I don't take the laws of nature to be necessary or to be metaphysically contingent in the opposite words in which they do not hold, following the more traditional picture. But if you must have an answer, the 
question I would ask is how would you know about that, how could you know that the laws of nature couldn't be otherwise. And again here, I would be worried that the sources of our knowledge or sources of our beliefs are deficient. That we could not really know that.

\section{RMR: So: in your book you see laws of nature as metaphysically contingent?}

In the book yes. I mean what I should be saying exactly is that's how I put it in the book. As far as I am concerned, for the writing, I do not know. Because I couldn't know, cause I don't think we can know if it's metaphysically contingent or metaphysically necessary. I think the answer to that question is beyond the bounds of our knowledge. So, genuinely the answer is that we don't know at all.

RMR: So, we know that there are laws of nature, but we don't know what is their metaphysical status.

Well, it's reasonable to believe, at least if you just look at your face, the characterization of the laws of nature, we know that laws of nature don't simply describe the world, but extend to possibilities. Whether they are metaphysically necessary, whether they extend to every possibility, is something that we can't know.

RMR: Actually, you are developing a very important research: Geography Philosophy. Please tell us what you expect as a main goal of this project. Specifically, concerning the cross-cultural use of concepts like knowledge, belief, justice and so: Do you favor a pragmatist and contextualist position? Why?

So, The Geography Philosophy Project (GPP), is a Templeton funded project, so we received several million dollars by Templeton to develop this project, which involved about 100 researchers in 9 countries, Japan, Korea, China, South Africa, Morocco, Ecuador, Peru, Slovakia and the US. It's a big project. We have a website, Facebook page and a blog. So the goal of that project is to study the concepts of knowledge, understanding and wisdom across the world in depth. So what we want to 
do is really find two things: We want to find what's universal in the way people describe knowledge, the way people understand wisdom and the way people understand understanding. And we want also to find what varies and why these concepts might vary. We think it matters for various issues, it matters for philosophy because variation is significant for philosophy, if it turns out that our understanding of wisdom is very culture specific, is a way a group understands wisdom but other groups understands it very differently, then it's a mistake I think to start from one understanding of wisdom. I think it's very important to get into combined understandings of what wisdom could be, for example.

Universals also matter because if something is provided a full description that might be the starting place for theorizing either about the concept of knowledge or about knowledge itself. It might tell us about why we have the concept of knowledge and it might give us some insight not simply about the concept of knowledge but about knowledge itself. So, that's for philosophy but it also matters for other disciplines, for anthropology, for linguistics we are going to do a lot of work on the word knowledge and its translations, the word wisdom. It also matters for psychology and we are going to do a lot of work on the psychology of the wisdom. So it is an interdisciplinary project. We are trying to bring philosophers, which are empirically oriented, linguists, anthropologists, and psychologists with comparting philosophers, people having a foot in philosophy of other cultures together, to get a good understanding of these three notions. We are just at the beginning of the project so we'll see what comes out of that.

With respect to pragmatism, I tend to have pragmatic leanings with respect to concepts. I think concepts can be engineered to fulfill some needs, I'm not saying it's easy, but I think it's a reasonable project, I talk a little bit about that in the last chapter of my book. I think then the charges are often based on the concept of what we want to do on earth and that is pretty much a pragmatic issue towards concepts. It might as well be that the study of the concept of knowledge, wisdom and understanding, will give us better tools to make a choice between various ways of thinking about 
knowledge, understanding and wisdom, which is very much in line with the pragmatist project.

\section{RMR: About variability: Do you see viability connected to the topic of disagreement?}

Yes, definitely yes, I mean when there's disagreement, one explanation on why people disagree is because they are unreliable, they're unreliable at making judgments and you would expect disagreement. It's a very natural explanation of disagreement. Think about a noise thermometer. You've got two noise thermometers and you are just measuring the same substances or the same water with thermometer $A$ and thermometer B; the more noises there are the less reliable, the more noises there are the less likely they will give you the same measurement. So you can expand this idea concerning philosophical disagreements, the reason why we end up with philosophical disagreements is because we are just unreliable to get it right. It's not the only possible explanation; it is just one possible explanation of what's going on.

RMR: Do you think that empirical data demands universal acceptance, if it is the case that it's truth is unquestionable, although fallible? In other words: are empirical data better in this sense that a priori access?

Empirical stands and empirical research is fallible and is questionable. People make mistakes in collecting data, the interpretation of data is always a theoretical matter, so no data is foundational. Everything is a matter of interpretation and discussion, so in that respect in itself empirical data does not demand universal acceptance, it often has to be interpreted, if it can be interpreted in many ways. With that said, it is an important component of philosophical discussion and what is not acceptable in my mind is to ignore or reject empirical data, just because it does not fit one's views. So that's wrong, but there is almost always room for disagreement about the significance of empirical findings and that's true not only in philosophy but also true on science. It's often, not always, the case that the evidence is ambiguous, not decisive, called for interpretation, 
called for further assistance. That's the way an empirical science works. That's also true of the contribution of experimental data to philosophy, noted from there.

You asked me to compare empirical data and a priori access. I don't believe that, except in mathematics, I don't believe that there is very much a priori knowledge. I believe that a priori knowledge is a shallow in any interesting philosophical point of view. Maybe, we might argue that bachelors are male; we might know that a priori by thinking about the meaning of bachelor. There might be a few — supposing that there are any — there might be a few analytic truths that we can know a priori. My position is: if there are they are pretty much uninteresting for philosophy. It's not that a priori is better, except for mathematics, which I have no good understanding of in terms of epistemology, a priori knowledge is pretty much irrelevant for philosophy. So that's a fairly radical naturalist position on the matter. It's not a new position of course. It was a new position back in the 70's. And it's a position that many naturalist have embraced since then.

\section{RMR: One of your main arguments in PWIPB is the argument of Unreliability: How do you understand unreliability? Could some snap judgement (aka intuitions) be unreliable, and notwithstanding useful?}

So I do understand reliability pretty much along the lines of Goodman's notion of reliability and his work on reliabilism. So judgements are reliable if they are more likely than not to be true and / or supposing they follow from premises, if the premises are true then they are more likely than not to be true. So it's very much along the line of Goodman's explanation. Snap judgements can be reliable. Some snap judgements are reliable and some of them are unreliable. So there is no necessary connection between snappiness, so to speak and reliability. Even if not reliable they could be useful, it just depends for what. Could they be useful for philosophy? Maybe, it depends for what. Now it's hard for me to answer the question so abstractly. If you tell me useful for this or that, then I could probably have more definite answers, but useful for something abstract like that I don't really know. 


\section{RMR: We need some example.}

An example, yes, but more so a goal. So nothing is useful, period. Things are useful for other things. Are they useful for what? If you specify the question a little I could give you a more precise answer.

RMR: Concerning the ethical problems present on the practice of science and philosophy: Do you think that there are some principles or norms that must be respected? Why? How do you see a good scientific practice? Do you think there is some kind of virtue related with this practice, for example from a deflationist point of view?

I do think there are indeed ethical norms at play in science. I think there ate ethical norms at play in any intellectual activity; in science, fraud is one of the worst things one can do and it's that that's on gaging what is known as questionable research practices (QRPs). These practices increase the unreliability of your research, what was actually acceptable a few years ago because people didn't know better, in that they are committing an act of negligence and that's wrong. So I think ethical norms are governing any intellectual activity or scientific activity, I think that is widely recognized by scientists. Why are they? Well, because ethical norms are a part of every aspect of life including thinking. You know lying is wrong, and fraud is a form of lying. So norms against lying are going to be applicable to scientific activity. Negligence is often wrong because it leads to bad consequences. For example, negligence and science: not respecting proper epistemic norms in science is going to be wrong and will have bad consequences and that kind of thing. So I do think indeed that ethical norms apply to science, philosophy and any intellectual activity and they apply to any intellectual activity because they are activities. Practical norms apply to any activity, including intellectual activities. So that's basically the view and good scientific practices are hard to describe. They depend a bit on the domain. In my mind it involves great care with collecting evidence and being open to all the evidence instead of being biased and only 
sharing the cherry-picking, the data that supports ones views. There's nothing I dislike more than when philosophers cherry-pick evidence instead of looking at the full body of evidence. I could give names, but I won't do it. Also I tend to and I've grown into disliking, flights of speculation. I much prefer scientists who are extremely careful in their intellectual speculations on the basis of data. There might be room for different types of scientists, but I think it's important not to overstate the significance of empirical results and also not to overstate the strengths of the evidence one might have. I think scientists are often guilty of that. They tend to over-reach. They don't analyze the complexity of science or the limitation of the evidence. They have the noisiness of the evidence; the uncertainty comes with doing science. They often want to draw conclusions that go way beyond the light of the data. Avoiding this is an important component of good scientific practices, this is a form of virtue.

\section{RMR: Why do you believe they do that?}

I believe they do that because they get incentivized to do that, through free insurance, grants; people know you, they hear about you, you get invited to write books, you go on the radio, when you make extreme claims, when you go beyond the evidence. So the more you go beyond the evidence the better your career is going. So people are incentivized to actually engage in scientific practices. Overall this is actually not right, is a complicated matter because some of these things might sometimes, given the scientific community, be useful and contribute to increasing scientific knowledge. But I do suspect that it might be well more of an exception than the rule on average; this form of exaggeration is actually detrimental to science. But scientists are incentivized to do this.

\section{RMR: And when they do that, do they know what they are doing?}

I don't know about that, it's a good question. I don't know if they are exactly aware of that they are engaging in — speculation — or whether they are not specifically sensitive to the limitation of their knowledge. I think it varies a little bit: some of 
them just like speculating and are perfectly happy to speculate and will tell you they are speculating. Others just like a good understanding of their limitations of scientific knowledge.

\section{RMR: About that: How do you understand intellectual speculation? When you talk about intellectual speculation?}

It's making claims about things you really couldn't have evidence for. It does relate to my concern about philosophy. We talked about the bounds of philosophical knowledge earlier. I think it's the same in science, when you couldn't just have good evidence. Speculation starts when one starts making claims for which you just couldn't know. We just couldn't know the evidence or we just don't have the evidence or the evidence was bond to be ambiguous, to be very noisy. I think of claims about the evolution of language, we will just never know how language evolved; it's beyond the type of evidence that we will always have.

\section{M: So it is not only a problem of philosophy.}

No, I have the same attitude for science and philosophy. I think it's an attitude where we are telling people about the limitation of their knowledge and insisting that it's important to keep in mind the bounds of knowledge, not only in philosophy but in science. It's exactly the same attitude that I have in both cases and for me it's very important. It's one of the key aspects of my work and the work I've been doing is to highlight the bonds of knowledge. In that respect I clearly belong to the empiricist tradition in philosophy and Kant surprisingly belonged to this tradition, but Hume highlighted the limitation of knowledge and metaphysics. Kant highlighted his limitations of knowledge. All of that in this tradition belongs to things that we just can't know in philosophy or science. It's important to always have in mind the limitation of what we can do. 


\section{RMR: Do you think that there is philosophical knowledge?}

Yes, of course I think there is philosophical knowledge, but maybe not the philosophical knowledge that philosophers hope to get. So I think there is philosophical knowledge of a specific kind. We sometimes learn that some philosophical arguments are not very good. So there is negative philosophical knowledge.

\section{RMR: How is that?}

Well, you know, you might for example have a view that is used as an explanation in this or that. Then you might find out that can't really be true, because it just doesn't apply to these forms of explanations. So I think that most philosophers have come to check, someone says something and people come to learn "well, that just doesn't really work this way" and that's a form of philosophical knowledge. We just learn that some arguments put forward or some views that are put forward by some philosophers are actually unsatisfying for such and such reasons. That's a negative form of philosophical knowledge, if you want.

\section{RMR: It's like knowledge without object.}

Yes. I don't know if there is an object properly speaking. It's not learning something positive about something. It's learning in some way that you don't have knowledge of. You thought you knew that explanation when you don't know what explanation it is. You thought you had a very good argument for your ideas, if you are an idealist. Well, actually your argument is flawed in such and such respect. It is a form of philosophical knowledge. It's just a negative form of knowledge. And I think much

of philosophy is of that kind. Now that's one form of philosophical knowledge. Another form of philosophical knowledge is a bit different; it's knowledge which is intertwined with science. I think here we do have positive knowledge. I think philosophers make positive contributions to science and here again we do have positive contributions to the cores of knowledge, in methodology, in understanding of scientific concepts, in helping scientists improve their methods, improve their scientific concepts, 
to clarify their views, all of that. I think philosophers in science made many important contributions in the history of philosophy. But notice it is closely intertwined with science. You might use it; if you want to make a positive contribution to knowledge not simply getting one, you better be connected to science. The farther away you are from it the less likely it is that you are going to be straight up, and there won't be any knowledge there.

\section{RMR: How do you foresee philosophical development in the next twenty years? It's a kind of speculative question.}

The truth is that I don't know, but I wish I knew. I have no idea how philosophical knowledge [will evolve]. Over the last 20 years, I've learned that it's very hard to predict how philosophy evolves. I think philosophy is very faddish. I think facts matter a lot to philosophy. Philosophers congregate on a given topic for a few years and get bored with it and the move on to another topic. It's a pretty dim view of what philosophers do, of the sociology of philosophy. So it's pretty hard to predict what philosophers are going to be gravitating around. I can tell you about my hopes rather than my predictions. So I do hope that empirically-inclined philosophy will remain strong in philosophy. I do hope that more than a few philosophers will become more skeptical of some trends in metaphysics, which I think is very far from any empirical grounding or footing. I wish there would be fewer of this kind of speculation and more empirically-inclined philosophy. So that's a hope and that's the wish; whether that's going to happen, I'll do my best for that to be the case. But I can't really foresee the emergence of the future of philosophy.

\section{RMR: Finally, please tell us how you see the future of the Center for Philosophy of Science. What do you expect to do the following years here at Pitt?}

So here I have a better position because I have quite a lot of influence on how the Center for Philosophy of Science is going to be evolving in the coming years. So the center is in a great position right now. We are the first institution of our kind in the 
world. We get 8-10 fellows every year who stay for a month, or sometimes a year at the center. It's an extremely lively community, with workshops, talks, meeting groups. My goal first and foremost is to preserve that. I think in many ways the center is not perfect, nothing is perfect, but it is in extremely good shape. My goal is to make sure that it remains a place that is attractive for philosophers of science from all over the world and working on all topics. So I want it to remain a place that is attractive for philosophers that want to spend 6 months to a year doing philosophy of science and I want it to be opened to the whole world. So I'm very keen on people from Africa, Asia, Central and South America feeling welcomed here at the center. I don't want it to be a place dedicated to Anglo-American philosophy. I think it is very important that it remains an international space, where people can do philosophy of science. That's one of my goals and I think it has been like that and it will remain like that. We have a lot of workshops and I want to make sure that the workshops we organize are really centered on current age issues on philosophy of science and that they really are pushing the boundaries of philosophy of science. I really welcome diverse traditions in philosophy of science, including what people are working on and the methods they are using. So as I've gotten older, I've grown slightly more pluralist for diverse methods than I used to be. I still don't welcome purely a priori traditions or metaphysical inquires but maybe in 20 years from now [laughing]. I think preserving the center as a prominent place where philosophers from all over the world can engage in cutting-edge philosophy of science is my goal. I do think we have all the tools to make that happen. We have the support of the University of Pittsburgh; so far it's been a well-organized center and my people have been happy here. I want to preserve that tradition.

Pittsburgh, Pennsylvania. March 18th, 2019. 